Gut, 1962, 3, 312

\title{
Betamethasone enemata in ulcerative colitis
}

\author{
S. G. FLAVELL MATTS ${ }^{1}$
}

From the Royal Hospital, Wolverhampton

EDITORIAL SYNOPSIS In this series a very large therapeutic dose of corticosteroid was administered by retention enemata. For the first week the author gave the equivalent of between 300 and $750 \mathrm{mg}$. of cortisone daily and for the next three weeks 150 to $375 \mathrm{mg}$. daily. The results were excellent but systemic effects were noted in all who received more than the smallest dose used.

The value of local therapy in ulcerative colitis has been well established, using either the slow drip method (Truelove, 1956; Watkinson, 1958) or the one-dose bag method (Matts, 1960a, 1960b, 1961a, 1962), and using these methods an improvement rate up to $88 \%$ has been reported (Matts, 1961a). The introduction of a stable solution of betamethasone phosphate (Glaxo) is of interest to workers in this field for two main reasons. First, it is possible that improvement in results may be obtained by using alternative steroids and thus their trial is justified in this connexion. Secondly, the development of partial resistance to a particular steroid after prolonged local use in certain skin diseases has been reported (Vickers and Tighe, 1960; Vickers, 1962) although this difficulty has been overcome by varying the local steroid used. It is possible that this same resistance will develop to steroids applied locally to the colonic mucosa, and indeed my own observations in several cases in which prolonged local therapy was used tend to support this view.

The trial which is reported here consisted of using a solution of betamethasone in different concentrations applied intrarectally by the method previously described (Matts 1960a, 1960b, 1961a, 1961b, 1962) to four groups of patients suffering from ulcerative colitis.

\section{METHOD}

Patients were taken in four groups of 12 by a method of random selection. They were all cases diagnosed as ulcerative colitis by symptoms, sigmoidoscopy, barium enema findings, and negative stool cultures. All cases were judged to be in relapse because of the presence of diarrhoea with blood and mucus in the stools, the appearance of active ulcerative colitis sigmoidoscopically, and a raised E.S.R. with lowered haemoglobin. These major findings were supported by the general feeling of

'In receipt of a grant from the Birmingham Regional Hospital Board. the patient, the effect on the psyche, loss of appetite, the presence of abdominal pain, nausea and vomiting, general malaise, and weight loss. A rectal biopsy was taken in any doubtful case and interpreted according to the classification of Matts (1961b). No cases of fulminating colitis were included in this series.

Twelve patients were treated with enemata containing $10 \mathrm{mg}$. betamethasone, 12 with $7.5 \mathrm{mg}$. enemata, 12 with $5 \mathrm{mg}$. enemata, and 12 with $4 \mathrm{mg}$. enemata. All patients were instructed and treated similarly. They received the enemata night and morning for one week and then at night only for a further period of three weeks. No other therapy was given. Results were taken at the end of the four weeks by reassessing all the previous findings. Four classifications were made and the patients placed, namely, 1, free of symptoms and signs, 2, improved, 3 , same, and 4 , worse.

RESULTS

The results are set out in Table I.

\section{DISCUSSION}

The results with the $10 \mathrm{mg}$., $7.5 \mathrm{mg}$., and $5 \mathrm{mg}$. enemata are all good, and the initial response in this small series verges on $100 \%$ improvement. This high percentage of improvement has been reported by Truelove (1960) when using systemic and local steroids combined but by no one using local steroids alone. There is a sharp fall in improvement in the group treated with $4 \mathrm{mg}$. enemata. The presence of side-effects of therapy in a high percentage of cases suggests very strongly that a significant amount of betamethasone has been absorbed into the body causing adrenocortical suppression. It has been shown that adrenocortical suppression occurs when a dose exceeding $37.5 \mathrm{mg}$. of cortisone or its equivalent in more potent steroids is given systemically (Shuster and Williams, 1961). The equivalent of this dose is approximately $1.0 \mathrm{mg}$. of betamethasone, 
TABLE I

RESULTS IN THE PRESENT SERIES

Betamethasone

Enemata

Side-effects of Therapy

\begin{tabular}{lr}
\hline $\begin{array}{l}\text { Group I } \\
\text { Free of symptoms and } \\
\text { signs }\end{array}$ & $12 \mathrm{mg}$. \\
Improved & \\
Same & 0 \\
Worse & 0 \\
\end{tabular}

All patients showed moon face and two had acne

$\mathbf{0}$

Group II $7.5 \mathrm{mg}$.

Free of symptoms and 11 signs

Improved

Same

Worse

1
0

Group III

Free of symptoms and $5 \mathrm{mg}$. signs
Improved

Same

Worse

\section{1}

Froup IV of symptoms and $4 \mathrm{mg}$. signs

Improved

Same

Worse

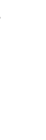

$\mathbf{0}$
$\mathbf{0}$
$\mathbf{0}$

All patients showed mocn face and three had acne Moon face

$$
\mathbf{0}
$$

All patients had moon face and one had acne Moon face $\mathbf{0}$
$\mathbf{0}$

Moon face in four patients

Moon face in one patient, acne in one patient Moon face in one patient 0

and the presence of moon face in many of the patients leads one to believe that a dose of this magnitude could well have been absorbed from the colon. To confirm this clinical impression a trial was carried out to determine adrenocortical function before and after therapy with betamethasone enemata (Matts, Walters, Kelleher, and Wharton, unpublished observations), and preliminary results suggest that all precautions should be taken in patients treated with betamethasone enemata as though they had received systemic steroids.

It appears from the results that the beneficial result of the enemata containing $5 \mathrm{mg}$. or more of betamethasone is due to a combined systemic and local effect. A possible explanation of the apparently poorer results with the $4 \mathrm{mg}$. enemata is that there is no longer a significant amount of betamethasone being absorbed. This, of course, will need confirmation by betamethasone absorption studies.

These conclusions raise the interesting problem of the place of betamethasone enemata in the treatment of ulcerative colitis. There is already an effective method of local therapy using prednisolone enemata (Matts 1960a, 1960b, 1961a) which I have not observed to cause any systemic signs of steroid absorption when used in more than 300 cases. No ill effects have been noted by stopping therapy suddenly and no special precautions have been needed. This method has been shown to give an

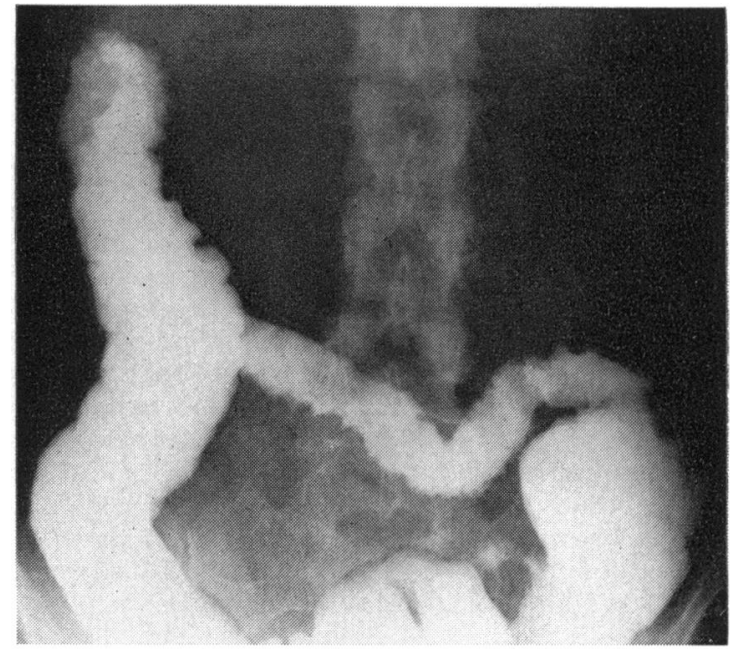

FIG. 1. Initial barium study showing the ulcerated area in the transverse colon.

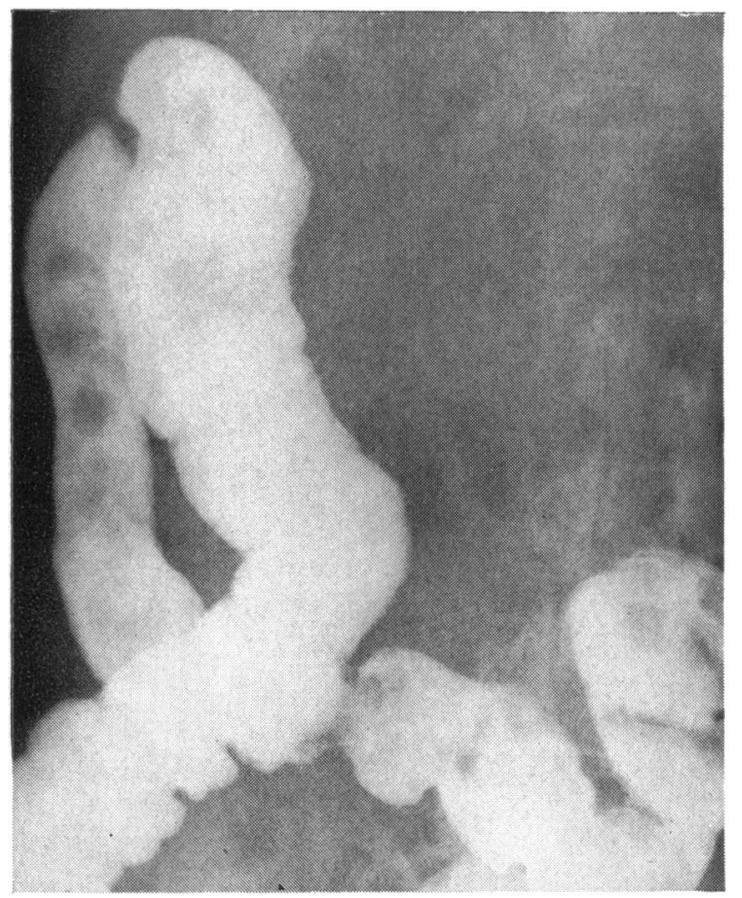

FIG. 2. A repeat barium study showing the improvement in radiological appearances.

$88 \%$ improvement rate in a fairly large number of cases (Matts, 1961a). However, in cases of generalized colitis there may be times when the enemata will not reach the whole colon (Matts and Gaskell, 1961), and it is in such cases that the betamethasone enemata should be particularly beneficial. One such case was included in the $5 \mathrm{mg}$. betamethasone series. 
A woman of 29 with a five-year history of ulcerative colitis had been treated unsuccessfully with prednisolone enemata and, when referred, was in relapse with bowel action 10 or 12 times daily and passing much blood. Sigmoidoscopy was atypical but biopsy confirmed active ulcerative colitis according to the classification of Matts (1961b). The initial barium enema study is shown in Fig. 1 in which the ulcerated area is shown to be in the transverse colon, possibly partly out of reach of the enemata. One month's therapy with betamethasone produced remarkable improvement, both in symptoms and signs. A repeat barium study is shown in Fig. 2, and this illustrates the great improvement in radiological appearances. As this patient had already failed to improve with prednisolone enemata, it is likely that her response to the betamethasone was due to systemic and local effects. A remote possibility would be that the betamethasone has some more specific effect in this type of colitis but there is no evidence to support this view.

Another type of case in which it would be of value is that in which relapses had been frequent. The possibility of steroid resistance appearing would be suggested by a poor response to repeated therapy with the same steroid. I have seen two patients who would fit into this category.

In view of the almost invariable appearance of signs of steroid absorption it is recommended that "the possibility of adrenocortical suppression is kept in mind in all patients treated with betamethasone enemata. This systemic effect may not be a bad thing in certain cases, and no ill effects should result provided appropriate precautions are taken as with ordinary systemic steroid administration.

I would like to thank Glaxo Laboratories Limited for generous supplies of betamethasone enemata, and Sister Martin, Sister Lovatt, and nurses of the Royal Hospital for their help. I should also like to thank Dr. J. V. S. A. Davies, Dr. P. A. Thorn, and Dr. E. J. Blair for permission to treat their cases.

\section{REFERENCES}

Matts, S. G. F., (1960a). Local treatment of ulcerative colitis with prednisolone-21-phosphate enemata. Lancet, I, 517-519. (1960b). Local therapy of ulcerative colitis. Proc. roy. Soc. Med. 53,650 .

- (1961a). Intrarectal treatment of 100 cases of ulcerative colitis with prednisolone-21-phosphate enemata. Brit. med. J., 1, 165-168.

- (1961b). The value of rectal biopsy in the diagnosis of ulcerative colitis. Quart. J. Med., 30, 393-407.

- (1962). Combined steroid therapy of fulminating ulcerative colitis. Brit. med. J., 1, 1045-1048.

- , and Gaskell, K. H. (1961). Retrograde colonic spread of enemata in ulcerative colitis. Ibid., 2, 614-616.

-, Walters, G., Kelleher, J., and Wharton, B. A. Adrenocortical and pituitary function after intrarectal steroids. Unpublished.

Shuster, S., and Williams, I. A. (1961). Pituitary and adrenal function during administration of small doses of corticosteroids. Lancet, 2, 674-678.

Truelove, S. C. (1956). Treatment of ulcerative colitis with local hydrocortisone. Brit. med. J., 2, 1267-1272.

- (1960). Systemic and local corticosteroid therapy in ulcerative colitis. Ibid., 1, 464-467.

Vickers, C. F. H. (1962). Double-blind trial of betamethasone. Ibid., 1, 156-157.

, and Tighe, S. M. (1960). Topical triamcinolone in eczema. Brit. J. Derm., 72, 352-354.

Watkinson, G. (1958). Treatment of ulcerative colitis with topical hydrocortisone hemisuccinate sodium. Brit. med. J., 2 , 1077-1082. 